
derivative work. doi:10.1017/S1474746421000038

\title{
Constructions of Undeservingness around the Figure of the Undocumented Pregnant Woman in the French Department of Mayotte
}

\author{
Nina Sahraoui \\ Center for Sociological and Political Research in Paris, CRESPPA-GTM, CNRS, France \\ E-mail: nina.sahraoui@cnrs.fr
}

This article examines how Comorian pregnant women in Mayotte, a French overseas department in the Indian Ocean, came to embody an unwanted presence as irregular migrants due to their children's and their own potential claims to belonging, while they are entitled by law to access perinatal and maternal care. This article argues that framing undocumented pregnant women as a threat led to significant shortcomings in perinatal care delivery and that those shortages in turn worsened access to healthcare services for the Mahoran-French population as well, exacerbating feelings of resentment towards Comorians. Drawing on this case-study, the article foregrounds the malleability of the CARIN criteria (Control, Attitude, Reciprocity, Identity and Need), a theoretical tool to analyse ideas related to deservingness, by demonstrating how actors re-think the meanings of 'identity', 'control', 'attitude' and 'need' and assign different weights to them in the context of a dominant frame of undeservingness.

Keywords: Migration, deservingness, healthcare, Mayotte, France.

\section{Introduction}

'There aren't many French people who give birth, meaning not many Mahorans. So it's on its way to disappear. Because you see in the schools there are our cousins, schools are full with them. So it creates a bad atmosphere.' (Najma, healthcare assistant, Mayotte dispensary)

The cousins that Najma, a Mahoran healthcare assistant, refers to are Comorians. Mayotte is one of the four islands of the Comorian archipelago in the Indian Ocean. This French department of 256,500 inhabitants (INSEE, 2019) shares undeniable historical and cultural links with the neighbouring Comorian islands, which formed the Republic of Comoros in 1974 after gaining its independence from France. The people of Mayotte having voted against independence, France organised a second referendum in 1976 specifically for the island, on the basis of which the island remained outside the newly independent Comorian State. Najma, whom I interviewed in 2017 in one of the island's dispensaries, thus complained about the presence in Mayotte of people from the neighbouring Comorian islands. She considered that there were too many 'cousins' around and that Mahorans' access to public services, such as schools, suffered as a consequence. The healthcare system in Mayotte is at the centre of the tension as to which categories of the population can legitimately access social services. Maternity care in particular is the issue 
around which these tensions are most heightened. With a rising number of births, reaching 9,800 in 2017 (INSEE, 2017), access to perinatal and maternal care by Comorians in Mayotte became a contentious issue. Prominent in these debates is the figure of the Comorian pregnant woman coming, allegedly, to give birth in Mayotte. In the context of intensely politicised discourses, undocumented pregnant women came to embody an unwanted presence as irregular migrants due to their children's and their own potential claims to belonging, besides representing, as pregnant women, bodies deserving of healthcare. Drawing on the case-study of perinatal and maternal healthcare, this article examines the tensions that unfold within migrants' access to healthcare in Mayotte, through the theoretical lens of deservingness.

This article examines how deservingness is qualitatively understood by drawing upon heuristic tools that were first identified through quantitative research into public attitudes towards the social legitimacy of different social groups receiving welfare benefits and accessing social services - the CARIN criteria: Control, Attitude, Reciprocity, Identity and Need (Van Oorschot, 2008; Van Oorschot et al., 2017), as further detailed in the review article of this themed section. Laenen, Rossetti and van Oorschot argue that the people who are judged as more deserving of social welfare are those perceived to have little or no personal control for getting in or for getting out of their situation'; 'those that are seen as grateful and compliant' (attitude); 'those with higher perceived contributions to society in the past, present or future' (reciprocity); 'those that are perceived as belonging to one's in-group' (identity) and 'those who are perceived to have high financial or health needs' (2019: 9). This article argues that the media-inflated discourse of the Comorian pregnant woman framed as a threat leads to significant shortcomings in maternity care delivery. It demonstrates how the CARIN criteria are mobilised in contrasted ways by social actors and healthcare professionals against the background of this prevalent framing of undeservingness. I argue that the meanings attached to the different criteria are highly malleable and shaped by a priori judgements of (un)deservingness. Overall, a qualitative approach to migrants' deservingness thus demonstrates that social actors construct decisive hierarchies among these criteria in relation to the broader socio-political context.

This article draws on fieldwork conducted in Mayotte from mid-April to mid-July 2017. I conducted interviews and participant observation with healthcare professionals (mainly midwives and healthcare assistants), for a total of forty interviews in the main maternity ward of the hospital in Mamoudzou and in one of the four dispensaries. I also joined the mobile healthcare unit of a local association on its trips across the island. The latter gave me the opportunity to interview forty Comorian women who were coming to see the midwife; the aim of the health truck being to provide access to a free consultation with a midwife and facilitate women's inclusion in the regular healthcare system. In addition, I conducted fifteen interviews with various stakeholders, from health authorities to social security services to local and national NGOs. All the midwives I interviewed were from metropolitan France, White and with rather brief professional experience in Mayotte owing to high staff turnover. All Mahoran healthcare assistants were Black; some had completed their studies in metropolitan France; and most had several years of working experience.

The first section examines the portrayal of undocumented pregnant women, conveyed by media representations, that provides the background against which perinatal and maternal healthcare services operate. The second and third sections reveal that the 
prevalence of a stigmatising discourse leads to the underfunding of perinatal care centres, which in turn exacerbates Mahorans' feelings of resentment by affecting the healthcare sector's overall functioning. A selection of narrated situations finally reveals the shifting meanings and hierarchies of value attached to different CARIN criteria.

\section{The figure of the undocumented pregnant woman and the healthcare system}

While the overseas department of Mayotte rarely features in national and international news, when it does it is mostly portrayed as a peripheral piece of French territory overwhelmed by irregular migration from the neighbouring islands. This portrayal relies on the assumption that migrants, and in particular women, come to Mayotte in the hope of bearing French children. These are typical depictions of undocumented pregnant women in Mayotte and of their intentions:

Faced with a wave of migrants this year, many of them pregnant women hoping to give birth in Mayotte so their children could become French. (Reuters, 2018)

8,000 kilometres from Paris, it's a maternity ward on the verge of implosion. In the maternity ward of Mamoudzou in Mayotte, the number of births has skyrocketed, namely because of the arrival of Comorian women willing to give French nationality to their newborns ${ }^{1}$. (AFP and 20 minutes, 2018)

Yet in contrast to such recurrent media depictions, there exists no automatic birth right citizenship in France; rather, children born in France become French nationals as teenagers, at age thirteen at the earliest, on condition of continuous residency since the age of eight. Many journalists give in to simplistic depictions of women's mobility within the Comorian archipelago. These portrayals obscure, on the one hand, the importance of traditional local mobilities across the islands, mostly owing to family ties (Geisser, 2016), and reproduce, on the other hand, the idea that undocumented women have necessarily arrived recently. In contrast, previous research (Math and Duflo, 2019), as well as results from this study, suggest otherwise. The high number of foreign women who give birth on the island is due more to barriers to regularisation than to the number of recent arrivals (Sahraoui, 2020a). Yet the representation of Mayotte as constantly facing new arrivals does produce performative categories that are mobilised by local actors and engender political and material implications in terms of healthcare delivery to pregnant women. This discourse, carried out by Mahoran politicians, was equally adopted by politicians at the national level, so that in 2018 France passed a restriction on future access to French nationality of children born in Mayotte by making it conditional on the legal status of one of the parents at the time of the birth (Duflo, 2019).

Caught in the migration debate, the perinatal and maternal healthcare services of Mayotte represent the bulk of healthcare services on the island, as neonatal and maternity care accounts for 61 per cent of all hospital activities (Chambre Régionale des Comptes Mayotte, 2019). The sector is composed of a network of twenty-one 'mother and child' care centres (Protection Maternelle et Infantile, PMI) as well as five maternity wards related to the hospital. The main ward is situated in the Mamoudzou hospital, with four annexes located across Mayotte. The financing of the hospital stems from global envelopes of State 
subsidies and the PMI network is funded by the departmental council. The State Medical Aid (AME) that gives undocumented migrants the possibility of having some of their healthcare expenses covered by social security after three months of residency does not apply in Mayotte. Pregnant women, however, have access to perinatal and maternal healthcare even if undocumented. Yet, the following section explores how the political instrumentalisation of the figure of the undeserving undocumented Comorian woman seeking to give birth in Mayotte led to the underfunding of the whole sector of perinatal care on the island.

\section{Perinatal care centres stigmatised for attending undocumented patients}

The PMI centres were financed by the State before Mayotte became a formal department. The process of 'departmentalization' led to the transfer of the PMI governance to the departmental council, composed of the local Mahoran elite, and thus to its budget. Healthcare services to pregnant women, crystallising tensions concerning undocumented migration, witnessed political manoeuvres around its financing. The metropolitan doctor at the head of the network of PMI centres, in his position for a year and a half at the time of the interview, analysed the situation in terms of political calculation and financial reciprocity aimed at securing votes:

If we sum up PMI centres and child welfare programs, it represents 10 to $15 \%$ of the department's budget for a population that is neither from the department, nor in its majority. Elected representatives are elected. And the foreign population doesn't vote. So it's not completely illogical to tell people you pay taxes and with these taxes we'll build roads and we won't provide care to those who have nothing to do with you.

The social security services I interviewed ${ }^{2}$ in 2017 indicated that between 25 and 30 per cent of the patients attending the PMI health centres possessed a social security number, meaning that the remaining 70 to 75 per cent of patients were not registered within the national healthcare coverage scheme; anyone who is French or a regular resident can register in Mayotte. Healthcare professionals were caught in the midst of this political battle over who should pay for the healthcare of those labelled 'foreigners'. Although these categories do not entirely overlap - a Comorian with a residency card can register with the national healthcare coverage scheme while a Mahoran might not be registered if s/he has not completed the necessary administrative procedures - they are widely mobilised and have become performative. Mariele, a metropolitan midwife at one of the PMI centres, deplored the crisis that resulted from the intentional underfunding of perinatal healthcare services:

The departmental council considers that it's not its responsibility to pay the personnel and the equipment for people who do not find themselves in a regular situation, that this is on the State. (... I I think that until the State gives us what it costs to attend to people who have no affiliation, the departmental council won't use its budget.

While undocumented women in metropolitan France might experience difficulties in accessing specific PMI centres (GISTI, 2004), by law these health centres attend all pregnant women and children under six without administrative discrimination 
(Davoudian, 2018). In Mayotte, the significant share of non-registered patients, but above all the detrimental political context, has led to the stigmatisation of the PMI health centres, associated with servicing allegedly undeserving pregnant women. At the political level, their undeservingness is framed in terms of lack of financial reciprocity, leading in practice to the underfunding of the health services that these women attend. For most of 2017, the network of PMI centres remained understaffed, with worries growing at the approach of the usual 'summer departures' caused by the high turnover of metropolitan healthcare personnel on the island. Laure, one of the very few working on the island for over ten years, shared her anxiety:

There's the problem of the departmental council that currently obstructs all recruitments at the level of the PMI. I'm not a nurse but I know that there must be about 50 to $60 \%$ of the nurses missing at the moment, notably in Kawéni, so there's a big problem in Kawéni [a suburb of Mamoudzou]. And at the level of the midwives it's more or less the same.

Grossly understaffed, the PMI centres also suffered shortages of equipment and basic resources. In light of the material consequences of the department's policies, midwives were left helpless. Aurélie, a metropolitan midwife employed in one of the island's busiest health centres, lamented:

In a tacit manner, there's a policy, a bit peculiar, regarding everything that concerns migrants, patients who are irregular. (...) We shouldn't have to deal with their political problem, if they don't like it that they are undocumented patients that's not our problem. We need to do our job and I think that what we have in the PMI is worse than a humanitarian situation in terms of how we work.

The 'humanitarian situation' Aurélie mentioned was particularly worrying during the early summer of 2017, when healthcare professionals of the PMI network jointly published an open letter asking for the State to step in to ensure continuity of care $^{3}$. Meanwhile, they also recounted episodes that had occurred during even more desperate weeks earlier that year. The centres' needs ranged from ultrasound scanners to items of basic hygiene such as soap. During water shortages that affected the Southern half of the island over two months in 2017, hygiene became impossible to maintain, as Claude, a metropolitan midwife, remarked in an exasperated tone:

The minimum is handwashing and the departmental Council has been very greedy in paper towels and soap. So on top of that if you don't have water! And not much soap!

The situation escalated to the point where some PMI centres had to close, given that, despite the extent of needs in terms of vaccination and pregnancy monitoring, healthcare professionals had no means of ensuring patients' and their own safety due to a lack of resources. Aurélie explained how she and some of her colleagues had to discontinue their work in the face of such unacceptable conditions:

We used our 'right to withdraw' several times because we had no equipment or there wasn't enough of us. When you don't have basic material resources and you can't guarantee patients' 
security in terms of the treatments, even if it's about pregnancy monitoring there are some invasive examinations, even the smear tests we stopped them because we didn't have anything to decontaminate, so it's not satisfactory.

Such extreme lack of resources, though to a large extent resulting from the political struggle described here, reinforced the image of the PMI services as being overwhelmed by demand, and thus fed into this representation of uncontrolled immigration of pregnant women, highly stigmatised and cast as undeserving. Hence the network of PMI centres became caught in a symbolic political battle. The construction over the years of symbolic boundaries (Lamont and Molnar, 2002) between Mahorans and Comorians resulted in deeply entrenched social boundaries. On the surface a competition between different levels of governance (that of the State and that of the department), the conflict revealed an underlying battle over whose presence is legitimate and who is deemed deserving of healthcare. The following section unpacks how Mahoran healthcare professionals framed this undeservingness.

\section{Shortcomings of the healthcare system and Mahorans' perceptions}

The intentional undermining of the PMI services due to their association with support for the undeserving neighbours exacerbated the healthcare system's malfunctioning, notably through ongoing staff shortages. The deterioration of working conditions in the public sector affected the quality of healthcare and fuelled Mahorans' frustration and resentment, directed towards Comorians. All of which created a vicious circle: the more the PMI and the hospital were overwhelmed, the more patients who had registered with social security, many of whom were Mahorans, were encouraged to consult medical practices of midwives and doctors outside the hospital or the PMI centres to avoid long waiting lists. Given that not every treatment could be fully reimbursed when consulting doctors in private practice, Mahorans resented the fact that possession of a social security card might paradoxically result in lesser coverage of one's medical costs. This situation pitted Mahorans and Comorians against each other, whereas in the past Mahorans seem to have focused more on denouncing the lack of investment by the French State than on blaming Comorians for the saturation of public services (Sakoyan, 2012). The words of Fati, a Mahoran healthcare assistant employed in the main hospital, illustrate how this resentment grew:

What gets on the nerves of Mahorans a lot here in Mayotte it's that you as a Mahoran, and I can understand because I'm Mahoran (... ) when we come to the hospital, you're Mahoran, you're told 'You have social security, so you go to the private sector. You pay for your private consultation and if you're not happy you get a plane ticket and you go to the Reunion Island or to the Metropole to get healthcare'. You see? That's all of this that creates frustration among Mahoran people.

The PMI health centres, understaffed and under-resourced, faced similar if not greater challenges than the public hospital; thus midwives often advised patients with social security to consult a midwife in the private sector, as the delay for an appointment was shorter and chances of adequate continuity of care were higher. For Mahorans used to the healthcare system in metropolitan France, this came as a surprise. Mariama, a Mahoran 
social worker who worked as healthcare assistant for several years in metropolitan France before moving back to Mayotte, recounted the following anecdote:

When I arrived in Mayotte, I asked about the PMI for my son, for the vaccines, and my sister tells me 'You shouldn't go there!' So I told her 'Why? With a child I've always been to the GP or in a PMI centre.' 'No, that's for the people from Anjouan [the closest Comorian island]. Everybody will look at you.'

It thus appears that, while Comorians were blamed for what was perceived as substandard conditions within the public healthcare system, Mahorans' practices of healthcare access followed a logic of social distancing from Comorians. Najma's reference to the unwelcome cousins in the introductory quote entails in this regard an apparent paradox for deservingness theory that considers social proximity (Willen and Cook, 2016) or identity (Laenen et al., 2019) as a factor that facilitates the construction of judgements of deservingness. In contrast, discourses by Mahoran social agents tended to combine a fully-fledged acknowledgement of Comorians' social proximity with a discourse as to their undeservingness to access the department's healthcare services. Yet the less Mahoran women use the PMI services, the more it is associated with a service 'dedicated' to undocumented migrants and thus stigmatised. Zainaba and Mariama, both Mahorans, believed that the reception conditions in the public sector caused many Mahorans to avoid the facilities altogether:

We tell ourselves: it's full at the hospital, it's better to go to the private sector.

It's also the case that Mahorans, most of them, say 'I don't want to go to the dispensary to be treated for free, waiting a whole day'.

This resentment towards Comorians translated into daily tensions in the maternity wards and perinatal consultation services. The following section examines how metropolitan midwives and Mahoran healthcare assistants navigated these tensions and, in the process, produced specific understandings of undeservingness.

\section{The malleability of the CARIN criteria within the tensed context of maternity care}

Against the background of Comorian migrations being portrayed not only as a social burden but as an existential threat to Mayotte's healthcare system, it appears that the CARIN criteria were invested with shifting meanings and different weights. The following anecdote recounted by Mahoran healthcare assistants shows that, since both Mahorans and Comorians can equally access the hospital to give birth, how they are treated becomes a contentious issue. Daily interactions in the maternity ward crystallised these tensions so that it was not the general lack of resources that was seen as the cause of unsatisfactory care, but Comorians, who were blamed for specific shortages. Mahoran healthcare personnel risked being perceived as participants in the allegedly favourable treatment that Comorian patients received. Favourable treatment merely meant the same 
treatment as everyone else, since the Mahoran patients described here believed they deserved 'more' care than Comorian patients on the basis of financial reciprocity.

HC 1: Sometimes we have patients, even from Mayotte, Mahorans, with whom sometimes...

HC 2: with whom it doesn't go well.

HC 1: it doesn't go well. Not because it doesn't go well professionally but it doesn't go well because we're Mahorans. We have to benefit from everything before...

HC 2: foreigners...

HC 1: foreigners. We work, we pay taxes, we have to benefit from everything. So sometimes they [Mahoran patients] can't understand us as workers from the hospital. (...) For instance, here, the habit of the ward, every Tuesday when bottles of water are delivered, we give one bottle to each patient. As we can't give one every day we tell them to fill it up when it's empty. But there are some, they go 'Me, I work, I pay taxes, so I demand a bottle of water every day. I won't bother filling it up over there, I'm not illegal. I don't drink tap water'. So it's a bit complicated sometimes.

If Mahoran healthcare professionals found themselves in a peculiar position and could be taken to task by Mahoran patients, metropolitan midwives, overwhelmingly white, female and young, also played a significant role in the production of the local moral economy of healthcare (Willen, 2015; Sahraoui, 2020b). A few months after these interviews were conducted, the hospital personnel called a strike to raise the government's awareness of the critical situation of health services in Mayotte. This time around, the medical personnel appeared to be divided along metropolitan vs. Mahoran lines. Mahoran strikers were reported to have displayed a willingness to bar Comorians from entering the hospital, having called upon the 'Women Leaders' [Femmes Leaders, a group of militant women who had advocated for Mayotte's departmentalisation] to ensure a selection at the hospital's entrance (Journal de Mayotte, 2017). The direction of the hospital, composed of metropolitan administrators and doctors, emphasised that it was not the role of the hospital to implement such distinctions. In line with this inclusive approach, Claude, employed in a PMI centre in the South of the island, disclosed how she attempted to reduce existing tensions by emphasising her universalist commitments:

When I arrived, all the Mahoran team [said] 'You, the Mzungu [Whites] you like to care for the Anjouannais [people from Anjouan] and the foreigners'. (...) In my profession, I'm here to take care of everyone. So we needed to change a bit the state of mind and even with your own colleagues, not the midwives but the clerical workers and healthcare assistants, so all the Mahoran team, to tell them and to make them understand. If there's an epidemic and if you don't vaccinate the 'foreign' children, meaning the Comorian cousins, the cousins from Anjouan, if you don't provide care to them, they'll get sick and will infect your own children.

Interestingly, Claude resorted to the notion of necessity to disarm the potential opposition to her inclusive stance in that she emphasised that Mahorans needed to make sure all children were vaccinated to protect public health on the island. Yet by no means 
did all metropolitan midwives adopt a public health-oriented stance that opposed the dominant undeservingness frame. In contrast, Véronique, a young midwife working in one of the dispensaries, shared her opinion as to Comorians' lack of deservingness on the basis of her assessment of patients' needs. Her reflections on the relative privilege of Comorian women led her to dismiss their alleged 'need', an opinion fuelled by judgements related to their attitude:

Last time, there was a woman, she didn't have nappies and she didn't ask for some so she left the baby in the shit. 'I didn't have nappies' [Mocking imitation] ( ... My colleague was commenting to me: 'They're so accustomed here that we give them everything' (...) And then, there are some people who say 'In Syria ... blablabla ... and the immigrants' ... But it's not comparable, they flee from war; in the Comoros there is no war. The Comoros are four times richer than Madagascar. Madagascar is the fifth poorest country in the world. The Comoros are the twentieth. So there are four times more resources in the Comoros than in Madagascar, and our main immigration is from the Comoros, so...

Véronique stigmatised undocumented Comorian patients by resorting to the discursive repertoire of the 'welfare scrounger', using perceptions around attitude to construct representations of the undeserving migrant. The midwife's peculiar use of the notion of need - stating a lack of need while mentioning that the Comoros are among the poorest countries in the world - also demonstrates how easily these CARIN criteria are filled with shifting meanings to sustain frames of undeservingness. At the same time, her discourse confirms the importance of the need criterion, as she senses the obligation to justify her views by dismissing any potential allegation as to Comorian women's needs. It equally hints at a decisive hierarchy among the CARIN criteria: as long as 'control' is assumed, with Véronique in this case considering that this migration was chosen, hardly any situation can qualify as presenting a 'need'. This is in line with results from quantitative studies that conclude by identifying a criterion of 'control over neediness' (Van Oorschot, 2006). However, the observed situation also differs from previous comparative research into undocumented migrants' access to various social services, which argued that in sectors of high professionalisation, such as healthcare and education, restrictive policies were most resisted by actors on the ground (Van der Leun, 2003: 123). The Mayotte-based case-study illustrates that a widespread anti-immigration political and media discourse can trump the resistance of professionals.

For migrants, as compared to other social groups, the 'control' criterion takes precedence and facilitates casting them as undeserving, since their very status as migrants is equated with having chosen their fate. In similar vein, Sophie, a colleague of Véronique, perceived an existing 'need', yet dismissed Comorians' rights to access free healthcare on the basis of the 'control' they were perceived to exert over their trajectories (see Slingenberg, 2021, for a similar finding in the analysis of the legal reasoning of the Supreme Court in the Netherlands). In the following quote Sophie explained her refusal to give a pregnancy test to a woman who came to the dispensary because her period was late:

I said 'We're not a pharmacy here, Madam. And it's the people who work who pay for what there is here. Even if you were pregnant, I wouldn't attend you; it's not an emergency. It's an emergency service here.' [sighs] If my period is late, I'll go and buy a pregnancy test in the supermarket, so she needs to do the same. If they have no money ... well they've already paid 
an amount of 600 euros to take the kwassa [small fishing boat used for passage to Mayotte] to come; yes they're flat broke. But after all, you want a child you need to have some money to take care of your child.

In the tense context of perinatal and maternity care in Mayotte the criteria of need and control were mobilised to sustain views as to Comorian women's undeservingness, following lines of thought that have elsewhere served to construct groups as deserving of social welfare (Jensen and Petersen, 2017; Laenen et al., 2019). These healthcare professionals engaged in an active neutralisation of criteria that they assumed others colleagues or potentially the interviewer - might consider as justifying certain forms of care. The need to make their differing interpretations explicit stemmed from an expectation that their views might contradict dominant moral sentiments within their profession.

\section{Conclusion}

This article started out with an examination of the discursive figure of the undocumented pregnant woman in Mayotte and presented the way this reflected on Comorian women, deemed undeserving of access to perinatal and maternal healthcare. The second section exposed how this framing led to serious shortages in the network of PMI health centres dedicated to young children and mothers. I then argued that the weaknesses of the healthcare system fuelled Mahorans' resentment, which led to examining the formation of judgements of undeservingness by Mahoran and metropolitan healthcare professionals. The article foregrounded the malleability of the CARIN criteria, demonstrating how actors easily re-think the meanings of identity, attitude, control and need and assign different weights to them in relation to a dominant frame of undeservingness.

Maternity care sits in this regard at the heart of the political battle as to who deserves to belong (and access social services). The shortcomings of the PMI centres are not only about access to shared resources but also about the boundaries of who is Mahoran and thus French. This political battle unfolds against the background of a peculiar 'us and them' context, in which 'they' are recognised as related to 'us', while their access to healthcare is not only undermined but also instrumentalised in the context of Mahorans' struggle to secure better integration with the French national entity. The deservingness criteria do not shed light per se on these dynamics, yet they help to uncover how antiimmigration narratives impact the meanings attached to these criteria, in this case the 'control' criterion trumping those criteria that might have fed into judgements of deservingness.

\section{Acknowledgements}

This article results from fieldwork conducted in the framework of the ERC funded EU Border Care project (Grant n. 638259) directed by Prof.Vanessa Grotti. I also would like to thank the Collège d'études mondiales (Fondation Maison des Sciences de l'Homme, Paris) for the support they provided to a research initiative Nora Ratzmann and I coordinated, enabling the organisation of the international conference 'The (Un)deserving Migrant?' in September 2019 at the FMSH which offered a stimulating academic space for the development of this article. 


\section{Notes}

1 Author's translation from French.

2 Interview with several officers of the Caisse de Sécurité Sociale de Mayotte (CSSM) in May 2017.

3 Source: 'Lettre ouverte des agents territoriaux de la PMI de Mayotte aux responsables politiques et à la population', sent June 26th 2017 to health authorities and shared by an interviewee.

\section{References}

AFP and 20 minutes (2018) 'Mayotte: à Mamoudzou, la «plus grande maternité d'Europe» est sous pression', https://www.20minutes.fr/societe/2238123-20180315-mayotte-mamoudzou-plus-grandematernite-europe-sous-pression [accessed 01.01.2021].

Chambre Régionale des Comptes Mayotte (2019) 'Rapport d'observations dèfinitives et sa rèponse : centre hospitalier de Mayotte', https://lejournaldemayotte.yt/wp-content/uploads/2020/05/Rapport-CRCCHM.pdf [accessed 01.01.2021].

Davoudian, C. (2018) 'Devenir mère sans papiers: à propos d'une pratique clinique en PMI', ERES Nouvelle revue de psychosociologie, 1, 25, 85-96.

Duflo, M. (2019) 'L'irresponsabilité de l'Etat', Plein Droit, 1, 120, $24-7$.

Geisser, V. (2016) 'Mayotte, si loin de Paris et pourtant si emblématique de nos "hypocrisies françaises"', Migrations Société, 2,164, 5-18.

GISTI (2004) Protection Maternelle et Infantile (PMI), https://www.gisti.org/doc/publications/2004/sanspapiers/pmi.html [accessed 01.01.2021].

INSEE (2017) Flash Mayotte $n^{\circ} 72$ - Septembre 2018, https://www.insee.fr/fr/statistiques/3607961 [accessed 01.01.2021].

INSEE (2019) 'À Mayotte, près d'un habitant sur deux est de nationalitè ètrangère', Insee Première $N^{\circ} 1737$, insee.fr/fr/statistiques/3713016 [accessed 01.01.2021].

Jensen, C. and Petersen, M. B. (2017) 'The deservingness heuristic and the politics of health care', American Journal of Political Science, 61, 1, 68-83.

Journal de Mayotte (2017) 'Revue de presse', https://www.mayotte.gouv.fr/content/download/8352/64467/ file/RP\%2010\%20novembre\%202017.pdf [accessed 01.01.2021].

Laenen, T., Rossetti, F. and van Oorschot, W. (2019) Why Deservingness Theory Needs Qualitative Research. Comparing Focus Group Discussions on Social Welfare in Three Welfare Regimes, SPSW Working Paper No. CeSo/SPSW/2019-01, Leuven: Centre for Sociological Research, KU Leuven.

Lamont, M. and Molnar, V. (2002) 'The study of boundaries in the social sciences', Annual Review of Sociology, 28, 167-95.

Math, A. and Duflo, M. (2019) 'Fantasmes et rèalitès dèmographiques', GISTI Plein droit, 1, 120, 16-19.

Reuters (2018) 'France and Comoros agree to end migration row', https://www.reuters.com/article/uscomoros-france-immigration/france-and-comoros-agree-to-end-migration-row-idUSKCN1 NC1S5 [accessed 01.01.2021].

Sahraoui, N. (2020a) 'Mayotte, l'éloignement des femmes enceintes', GISTI Plein Droit, 124, $39-42$.

Sahraoui, N. (2020b) Borders Across Healthcare: Moral Economies of Healthcare and Migration in Europe, Oxford and New York: Berghahn Books.

Sakoyan, J. (2012) 'Les mobilitès thèrapeutiques', Anthropologie and Santè, 5 | 2012, https://doi.org/10. 4000/anthropologiesante.1035 [accessed 01.01.2021].

Slingenberg, L. (2021) 'Deservingness in judicial discourse: an analysis of the legal reasoning adopted in Dutch case law on irregular migrant families' access to shelter', Social Policy and Society, doi: $10.1017 /$ S1474746421000075.

Van der Leun, J. (2003) Looking for Loopholes: Processes of Incorporation of Illegal Immigrants in the Netherlands, Amsterdam: Amsterdam University Press.

Van Oorschot, W. (2006) 'Making the difference in social Europe: deservingness perceptions among citizens of European welfare states', Journal of European Social Policy, 16, 1, 23-42. 
Van Oorschot, W. (2008) 'Solidarity towards immigrants in European welfare states', International Journal of Social Welfare, 17, 1, 3-14.

Van Oorschot, W., Roosma, F., Meuleman, B. and Reeskens, T. (eds.) (2017) The Social Legitimacy of Targeted Welfare: Attitudes to Welfare Deservingness, Cheltenham and Northampton: Edward Elgar Publishing.

Willen, S. S. (2015) 'Lightning rods in the local moral economy: debating unauthorized migrants' deservingness in Israel', International Migration, 53, 3, 70-86.

Willen, S. S. and Cook, J. (2016) 'Health-related deservingness', in F. Thomas (ed.), Handbook of Migration and Health. Cheltenham: Edward Elgar Publishing. 